\title{
Association Between C1q/TNF-Related Protein-1 Levels in Human Plasma and Epicardial Adipose Tissues and Congestive Heart Failure
}

\author{
Ying Yang ${ }^{a, b}$ Si Liu ${ }^{b}$ Rong-Yi Zhang ${ }^{b}$ Hui Luo ${ }^{c}$ Ling Chen ${ }^{b}$ Wen-Feng He \\ Rong Lei ${ }^{b}$ Mu-Rong Liub Hou-Xiang Hub Mao Chen ${ }^{a}$ \\ aDepartment of Cardiology, West China Hospital, Sichuan University, Chengdu, bDepartment of \\ Cardiology, Affiliated Hospital of North Sichuan Medical College, Nanchong, 'Department of \\ Cardiology, Nanchong Central Hospital, Nanchong, China
}

\section{Key Words}

Complement $\mathrm{C} 1$ q tumor necrosis factor-related protein $1 \bullet$ Congestive heart failure $\bullet$ Adipokine - Cytochrome P-450 11-hydroxylase 2 - Aldosterone

\begin{abstract}
Background/Aims: $\mathrm{C} 1 \mathrm{q}$ and tumour necrosis factor-related protein 1 (CTRP1) possesses antiatherogenic and anti-inflammatory effects. This study investigated whether the CTRP1 levels in the plasma and epicardial adipose tissue (EAT) were associated with congestive heart failure (CHF) and to disclose possible molecular mechanisms. Methods: Plasma and tissue samples were obtained from subjects with or without CHF. Plasma levels of CTRP1 were measured by ELISA. The mRNA levels of CTRP1 and inflammatory cytokines were detected by RT-PCR. The protein levels of CTRP1, aldosterone synthase (CYP11B2) and mitogen-activated protein kinase were examined by Western blotting. Results: The levels of CTRP1 in the plasma and EAT were higher in the CHF patients than those in the controls. There were no differences in the CTRP1 levels in cardiomyocytes between the CHF group and the non-CHF group. An exploratory survival analysis showed that higher CTRP1 values at admission were associated with a worse prognosis after discharge. CTRP1 increased the IL-6 mRNA level in H295R cells. CTRP1 recruited ERK1/2 and Jak-2 for aldosterone release by modulating the CYP11B2 protein level, and brain natriuretic peptide repressed the CTRP1-induced aldosterone release through the JAK2-STAT3 signalling pathways. Conclusion: The CTRP1 levels in the plasma and EAT were increased in the CHF patients. CTRP1 is involved in the pathogenesis of CHF by modulating IL-6 levels and aldosterone release.
\end{abstract}




\section{Cellular Physiology Cell Physiol Biochem 2017;42:2130-2143 \begin{tabular}{l|l|l} 
DOI: 10.1159/000479915 & and Biochemistry Published online: August 14, 2017 & $\begin{array}{l}\text { O 2017 The Author(s). Published by S. Karger AG, Basel } \\
\text { www.karger.com/cpb }\end{array}$
\end{tabular} \\ Yang et al.: Increasing CYP11B2 Levels and Aldosterone Release Through MAPK Signalling Pathways}

\section{Introduction}

Adipose tissue is an active endocrine organ that secretes a variety of molecules that affect both glucose metabolism and cardiovascular function [1]. Recently, epicardial adipose tissue (EAT) has emerged as a novel target for the stratification of cardiometabolic risk factors due to its unique location and multifaceted metabolic properties with systemic and local effects [2]. Epicardial fat and the heart share an unobstructed microcirculation, which suggests that paracrine or vasocrine interactions can occur $[3,4]$. C1q and tumour necrosis factor-related protein 1 (CTRP1) is a novel adipokine that is synthesized in arterial perivascular adipose tissue $[5,6]$. Recent data suggest that high levels of circulating CTRP1 are associated with metabolic syndrome, adiponectin deficiency, platelet aggregation, athero-inflammation and hypertension [7-11].

Congestive heart failure (CHF) is a complex clinical syndrome that results from any structural or functional impairment of the ventricular filling or ejection of blood [12]. The renin-angiotensin-aldosterone system (RAAS) plays a critical role in the regulation of sodium and water balance and stimulates myocardial and vascular fibrosis in CHF [13]. One study has shown that angiotensin II stimulated the secretion of CTRP1, which acted as an endogenous aldosterone-stimulating factor [11] It is well-known that brain natriuretic peptide (BNP) has a wide range of potent cardioprotective effects, including vasodilation, diuresis and the inhibition of the RAAS [14]. A recent study has shown that low levels of BNP could lead to reduced lipolysis and, thus, promote obesity [15]. However, the mRNA expression of multiple pro-inflammatory adipocytokines, including adiponectin, IL-1 $\beta$, IL- 6 and TNF- $\alpha$, were markedly increased in CHF patients [16]. In animal studies, an LPS treatment caused TNF- $\alpha$ - and IL-1 $\beta$-induced elevations of CTRP1 levels in adipose tissue [17].

However, the relationship between CTRP1 and CHF remains unknown. In the present study, we investigated whether CTRP1 levels in the plasma or EAT were associated with the prevalence of CHF and analysed the possible molecular mechanism of CTRP1 in the pathogenesis of $\mathrm{CHF}$.

\section{Materials and Methods}

\section{Subjects}

In total, 110 consecutive patients with CHF were enrolled from inpatients at the cardiovascular ward between September 2015 and July 2016. Patients were identified as CHF patients if they exhibited a clinical syndrome characterized by typical symptoms (e.g., breathlessness, ankle swelling and fatigue) that may be accompanied by signs (e.g., elevated jugular venous pressure, pulmonary crackles and peripheral oedema) [18]. The aetiology of CHF in all patients was assessed by echocardiography, cineventriculography, a radionuclide technique, cardiac magnetic resonance and coronary angiography [12]. Among the 110 patients with CHF, 25 patients underwent cardiac surgery, including 12 patients who underwent coronary artery bypass grafting (CABG) and 13 patients who underwent valvular replacement. In total, 50 control subjects were enrolled, including 40 subjects who were recruited from those having a health check at the outpatient clinic and 10 patients with non-CHF (NCHF) who underwent open-heart surgery for CABG $(n=4)$, valvular replacement $(n=4)$ or atrial septal defect repair $(n=2)$. We excluded subjects with acute myocardial infarction and diabetes mellitus and those taking glitazones, which are known as peroxisome proliferatoractivated receptor gamma ligands and stimulate fat tissue CTRP1 expression [19]. During the acute illness, the majority of the patients were treated with diuretics or vasodilators and a minority of the patients required positive inotropic agents. Most of the patients had been treated with several treatments, including angiotensin-converting enzyme inhibitors, angiotensin II receptor antagonists, beta-blocker, aldosterone blocker and diuretics, as the basic treatment.

The study protocol complied with the Declaration of Helsinki and was approved by the ethics committee of West China Hospital of Si Chuan University. Written informed consent was obtained from each patient before enrolment.

\section{KARGER}




\section{Cellular Physiology Cell Physiol Biochem 2017;42:2130-2143 \begin{tabular}{ll|l} 
DOI: 10.1159/000479915 & and Biochemistry & $\begin{array}{l}\text { O 2017 The Author(s). Published by S. Karger AG, Basel } \\
\text { www.karger.com/cpb }\end{array}$ \\
\hline andished online: August 14, 2017
\end{tabular} \\ Yang et al.: Increasing CYP11B2 Levels and Aldosterone Release Through MAPK Signalling Pathways}

\section{Blood Samples}

For the 40 control subjects, the blood samples were obtained from the outpatient clinic. For the patients with or without CHF, the blood samples were obtained from the patients upon arrival to the emergency unit (upon admission), $24 \mathrm{~h}, 48 \mathrm{~h}$, and at discharge. The samples were placed in chilled tubes containing EDTA$\mathrm{Na} 2\left(1 \mathrm{mg} / \mathrm{mL}\right.$ blood) and centrifuged at $3,000 \mathrm{rpm}$ at $4^{\circ} \mathrm{C}$ for $15 \mathrm{~min}$. The plasma was stored at $-80^{\circ} \mathrm{C}$ until further use.

Cardiomyocytes and adipose tissue acquisition

The tissue samples were obtained prior to the initiation of cardiac surgery from areas that had not previously been injured mechanically or cauterized. The right atrium myocardium was acquired from patients undergoing heart valve replacements. Two portions of adipose biopsy were harvested, including EAT near the right coronary artery ostium and subcutaneous adipose tissue (SAT) from the area of the chest incision. The tissue samples (average $0.5 \mathrm{~g}$ ) were rinsed with phosphate buffered saline and then divided into two portions. One portion was stored in liquid nitrogen for the RNA and protein isolation, and the other portion was immersed in neutralized formalin for the immunohistochemistry analysis.

\section{Cell culture}

H295R cells (China infrastructure of cell line resource, China), which are known as the human adrenal gland cell line, were plated at a concentration of $5 \times 10^{5} \mathrm{cells} / \mathrm{ml}$ in 24 -well plates and incubated for $24 \mathrm{~h}$. Prior to the experiments, the cells were starved with serum-free Dulbecco's modified Eagle's medium/Ham's F12 medium for $12 \mathrm{~h}$. The serum-starved cells were treated various times with $40 \mathrm{ng} / \mathrm{mL}$ of recombinant human CTRP1 (Abcam, USA) or BNP (ApexiBio, USA), and the culture supernatants were harvested at each time point.

\section{ELISA}

The concentrations of plasma CTRP1 (RayBiotech, USA) and aldosterone (Cayman Chemical, USA) were detected using commercially available enzyme-linked immunosorbent assay (ELISA) kits following the manufacturer's instructions. The ELISA intra-assay and inter-assay coefficients of variation were both $<5 \%$. The other parameters were obtained from the Biochemical Laboratory, Institute of Cardiology, West China Hospital. All samples were measured in triplicate.

\section{Immunohistochemistry}

Paraffin-embedded tissue sections were deparaffined, rehydrated in descending grades of alcohol, and stained with haematoxylin and eosin. Briefly, selected slides were incubated in $3 \% \mathrm{H}_{2} \mathrm{O}_{2}$ for 15 min and then blocked with normal goat serum for $20 \mathrm{~min}$. After the removal of the excess serum, the sections were incubated with the primary antibody (CTRP-1, 1:200 dilution; Abcam, USA) at $4^{\circ} \mathrm{C}$ overnight in a moisture chamber. The sections were then incubated with biotinylated secondary antibodies for 20 min, followed by avidin-biotin reagents for $20 \mathrm{~min}$. The slides were incubated with Diaminobenzidine (DAB) and counterstained for 1 min with haematoxylin. Light microscope observations and digital images were recorded. Positive staining of CTRP-1 was brown. The expression of CTRP-1 was semi-quantified by measuring the integrated optical density (IOD) of positively stained tissue using Image-Pro plus software 6.0 (Media Cybernetics, USA). The IOD of each tissue section was calculated based on four separate fields viewed at $\times 200$ magnification.

\section{Assessment of $m R N A$}

Total RNA was extracted from tissues using TRIzol reagent (Invitrogen, USA). Quantitative Real-Time PCR (qRT-PCR) was performed using a One Step SYBR PrimeScript RT-PCR Kit (Takara, Japan) and an ABI PRISM 7500 Sequence system (Applied Biosystems, UAS) according to the manufacturer's protocol. Glyceraldehyde-3-phosphate dehydrogenase (GAPDH) was used as an endogenous control. Fold changes in the mRNA expression level normalized to GAPDH were calculated using the comparative Ct method formula $2^{-\Delta \Delta C \mathrm{C}}$. The primers were designed using Primer Premier 6.0 software (Premier, Canada) with the following sequences: CTRP1, forward 5'- GCATCAGGCTCTGGCTTTG-3', Reverse 5'-CTGTGCCCTCCCCTGTGCT-3'; GAPDH, forward 5'-ATGGTGGTGAAGACGCCAGTA-3', Reverse 5'-GGCACAGTCAAGGCTGAG AATG-3'; TNF- $\alpha$, forward 5'- CCACCACGCTCTTCTGTCTACTG-3', Reverse 5'-GGGCTACGGGCTTGTCAC-3'; IL-1 $\beta$ forward 
5'- CCCTGCAGCTGGAGAGTGTGG-3', Reverse 5'-TGTGCTCTGCTTGAGGTGCT-3'; and IL-6 forward 5'TACATCCTCGACGGCATCTC-3', Reverse 5'-TTTCAGCCATCTTTGGAAGG-3'

\section{Western blot analysis}

Total protein extracts were prepared and then subjected to a Western blot analysis. After the SDSpolyacrylamide gel electrophoresis, the proteins were transferred onto nitrocellulose membrane and detected by the corresponding primary antibodies against cytochrome P-450 11ß-hydroxylase 2 (CYP11B2) (Santa Cruz, USA), U0126 (1, 4-Diamino-2, 3-dicyano-1, 4-bis(2aminophenylthio)butadiene)(Abcam, London, UK), SB203580 (4-(4-Fluorophenyl)-2-(4-methylsulfinylphenyl)-5-(4-pyridyl)1H-imidazole, $\mathrm{HCl}$ ) (Abcam, London, UK), AG490 (N-Benzyl-3, 4-dihydroxy- $\alpha$-cyanocinnamide)(Abcam, London, UK) and $\beta$-action (Beyotime, China), followed by horseradish peroxidase (HRP)-conjugated secondary antibodies. The proteins were visualized using the Enhanced chemiluminescence kit (Thermo, USA). Semi-quantitative analysis of the film was performed using the Image-Pro Plus analysis software.

\section{Statistical Analysis}

Numerical data were reported as the mean \pm SD or the median and interquartile range as appropriate. Continuous variables were analysed by one-way ANOVA or Kruskal-Wallis test to compare differences among the groups. Categorical data were analysed by the chi-square test. Variables were log-transformed as appropriate. A multiple regression analysis was performed to determine the independent relationships among the clinical parameters. For all analyses, a two-tailed p-value $<0.05$ was considered statistically significant. For an exploratory survival analysis, the patients were divided into two groups based on the median CTRP1 values. Then, Kaplan-Meier survival curves were constructed for each of the subgroups and compared. All statistical calculations were performed using SPSS software (version 16.0.2; SPSS Inc., Chicago, Illinois).

\section{Results}

\section{Patient characteristics}

The characteristics of the patients with CHF $(n=110)$ and the corresponding age- and sex-matched control subjects $(n=50)$ are described in Table 1 . Compared with the control subjects, the patients with CHF had greater values of DBP, HR, ALT, TC, TG, HDL-C, creatinine, uric acid, hsTnI, hs-CRP, HCy, BNP, TNF- $\alpha$, IL-1 $\beta$, IL-6, and left ventricular end-diastolic diameter (LVEDD) and lower values of ventricular ejection fraction (LVEF) ( $p<0.05$ for all parameters).

\section{Plasma CTRP1 levels were greatly increased in the patients with CHF}

The plasma CTRP1 levels were greatly increased in the patients with CHF compared with those in the control subjects at admission $(282 \pm 194 \mathrm{ng} / \mathrm{mL}$ vs. $153 \pm 37 \mathrm{ng} / \mathrm{mL}, p=0.008$, Fig. 1a). The plasma CTRP1 levels were elevated according to the severity of the NYHA class in the CHF patients (control: $153 \pm 37$, NYHA II: $256 \pm 115$, NYHA III: $280 \pm 112$, NYHA IV: $331 \pm 126 \mathrm{ng} / \mathrm{mL}, p=0.005$, Fig. $1 \mathrm{~b}$ ). We additionally subdivided the CHF patients into 2 groups of ischaemic cardiomyopathy and non-ischaemic cardiomyopathy. As the severity of the NYHA class increased, the plasma CTRP1 levels elevated in both patients with ischaemic (NYHA II: $253 \pm 114$, NYHA III: $270 \pm 112$, NYHA IV: $302 \pm 129 \mathrm{ng} / \mathrm{ml}$ ) and non-ischaemic (NYHA II: $260 \pm 128$, NYHA III: $290 \pm 117$, NYHA IV: $332 \pm 148 \mathrm{ng} / \mathrm{mL}$ ) cardiomyopathy. In addition, as the LVEDD value increased, the plasma CTRP1 levels elevated in the CHF patients (control: $153 \pm 37$, LVEDD<55 mm:241 \pm 113 , LVEDD $\geq 55 \mathrm{~mm}: 324 \pm 112 \mathrm{ng} / \mathrm{mL}, p=0.002$, Fig. 1c). However, the plasma concentrations of CTRP1 were not significantly different among the 3 subgroups according to the LVEF class (LVEF<40: 295 \pm 116 , LVEF 40 49: 300 \pm 115 , $\mathrm{LVEF} \geq 50: 272 \pm 123 \mathrm{ng} / \mathrm{mL}, p=0.9$, Fig. $1 \mathrm{~d}$ ).

\section{Changes in plasma CTRP1 values and other variables}

The plasma CTRP1 values in the CHF patients peaked upon admission, were significantly increased compared with those of the controls and quickly decreased after $24 \mathrm{~h}$ (Fig. 2). Other variables also changed following the treatment of CHF (Tables 1 and 2). 
Yang et al.: Increasing CYP11B2 Levels and Aldosterone Release Through MAPK Signalling Pathways

Table 1. Clinical features of patients with congestive heart failure, BMI, body mass index; SBP, systolic blood pressure; DBP, diastolic blood pressure; HR, heart rate; NYHA, New York Heart Association; ALT, alanine aminotransferase; TC, total cholesterol; TG, total triglyceride; HDL-C, high-density lipoprotein cholesterol; LDL-C, low-density lipoprotein cholesterol; HbA1C1, glycosylated hemoglobin; hs-TnI, high sensitive troponin; hs-CRP, high-sensitive C-reactive protein; BNP, brain natriuretic peptide; LVEDD, left ventricular end-diastolic diameter; LVEF, left ventricular ejection fraction; ACEI, angiotensin converting enzyme inhibitor; $\mathrm{ARB}$, angiotensin receptor blocker. Continuous values are shown as the mean \pm SD or median (interquartile range), as appropriate. ${ }^{*} \mathrm{p}<0.05,{ }^{* *} \mathrm{p}<0.01$ versus control

\begin{tabular}{|c|c|c|c|}
\hline \multirow[t]{2}{*}{ Characteristics } & \multirow[t]{2}{*}{ Control $(n=50)$} & \multicolumn{2}{|c|}{$\operatorname{CHF}(n=110)$} \\
\hline & & At admission & At discharge \\
\hline \multicolumn{4}{|l|}{ Demographic data } \\
\hline Age, years & $67 \pm 5$ & $68 \pm 8$ & \\
\hline Male gender, n (\%) & $29(58)$ & $63(57)$ & \\
\hline \multicolumn{4}{|l|}{ Etiology, n (\%) } \\
\hline Ischemic heart disease & $4(8)$ & $44(40)$ & \\
\hline Dilated cardiomyopathy & & $22(20)$ & \\
\hline Valvular heart disease & $4(8)$ & $15(14)$ & \\
\hline Hypertensive heart disease & & $11(10)$ & \\
\hline Hypertrophic cardiomyopathy & & $10(8)$ & \\
\hline Hyperthyroidism & & $4(4)$ & \\
\hline Myocarditis & & $4(4)$ & \\
\hline atrial septal defect & $2(4)$ & & \\
\hline \multicolumn{4}{|l|}{ Physical examination } \\
\hline Weight, kg & $67 \pm 9$ & $73 \pm 10$ & $66 \pm 10$ \\
\hline $\mathrm{BMI}, \mathrm{kg} / \mathrm{m}^{2}$ & $23 \pm 2$ & $24 \pm 3$ & $22 \pm 3$ \\
\hline $\mathrm{SBP}, \mathrm{mmHg}$ & $121 \pm 16$ & $131 \pm 29$ & $117 \pm 13$ \\
\hline DBP, mmHg & $74 \pm 11$ & $82 \pm 16^{*}$ & $71 \pm 9$ \\
\hline $\mathrm{HR}, \mathrm{bpm}$ & $73 \pm 8$ & $87 \pm 18^{*}$ & $71 \pm 9$ \\
\hline Atrial fibrillation (\%) & $0(0)$ & $15(14)$ & $15(14)$ \\
\hline \multicolumn{4}{|l|}{ NYHA functional class,n(\%) } \\
\hline I & & 0 & \\
\hline II & & 29 & \\
\hline III & & 48 & \\
\hline IV & & 33 & \\
\hline \multicolumn{4}{|l|}{ Laboratory examination } \\
\hline ALT, IU/L & $14(6-36)$ & $33(3-158)^{* *}$ & $28(4-56)^{* * *}$ \\
\hline $\mathrm{TC}, \mathrm{mmol} / \mathrm{L}$ & $1.0 \pm 0.5$ & $3.7 \pm 0.7^{*}$ & $3.3 \pm 0.6^{*}$ \\
\hline $\mathrm{TG}, \mathrm{mmol} / \mathrm{L}$ & $4.2 \pm 0.8$ & $1.0 \pm 0.2^{*}$ & $1.2 \pm 0.6^{*}$ \\
\hline $\mathrm{HDL}-\mathrm{C}, \mathrm{mmol} / \mathrm{L}$ & $1.3 \pm 0.3$ & $1.1 \pm 0.2^{*}$ & $1.0 \pm 0.2^{*}$ \\
\hline LDL-C, $\mathrm{mmol} / \mathrm{L}$ & $2.5 \pm 0.6$ & $2.2 \pm 0.5$ & $2.2 \pm 0.7$ \\
\hline Creatinine, $\mathrm{mmol} / \mathrm{L}$ & $62(27-85)$ & $108(34-875)^{*}$ & $77(30-145)^{*}$ \\
\hline Uricacid, $\mathrm{mmol} / \mathrm{L}$ & $280 \pm 74$ & $567 \pm 171^{*}$ & $386 \pm 113^{*}$ \\
\hline Fasting glucose, $\mathrm{mmol} / \mathrm{L}$ & $4.8 \pm 0.5$ & $5.2 \pm 2.4$ & $5.1 \pm 1.3$ \\
\hline HbA1C1(\%) & $5.2 \pm 0.2$ & $5.0 \pm 0.6$ & $5.1 \pm 0.3$ \\
\hline hs-TnI, $\mu \mathrm{g} / \mathrm{L}$ & $0.04 \pm 0.01$ & $0.1 \pm 0.04^{* *}$ & $0.05 \pm 0.02$ \\
\hline hs-CRP, mg/L & $0.3(0.08-6.1)$ & $4.8(2.6-22.5)^{* *}$ & $1.7(0.7-8.5)^{* *}$ \\
\hline $\mathrm{Hcy}, \mu \mathrm{mol} / \mathrm{L}$ & $13 \pm 5$ & $18 \pm 5^{*}$ & $18 \pm 4 *$ \\
\hline $\mathrm{BNP}, \mathrm{pg} / \mathrm{ml}$ & $14(10-23)$ & $2498(1143-5000)^{* *}$ & $788(81-2338)^{* *}$ \\
\hline Aldosterone( clinostatism), pmol/L & $135 \pm 30$ & $456 \pm 189^{* *}$ & $331 \pm 133 *$ \\
\hline TNF- $\alpha, p g / m L$ & $2.8 \pm 0.5$ & $6.8 \pm 0.7 * *$ & $3.5 \pm 0.2 *$ \\
\hline $\mathrm{IL}-1 \beta, \mathrm{pg} / \mathrm{mL}$ & $1.8 \pm 0.7$ & $13.5 \pm 5.2^{* * *}$ & $8.4 \pm 3.1 * *$ \\
\hline IL-6,(pg/mL) & $1.0 \pm 0.5$ & $16.7 \pm 6.5^{* *}$ & $5.3 \pm 2.1^{* *}$ \\
\hline \multicolumn{4}{|l|}{ Echocardiographic data } \\
\hline LVEDD, $\mathrm{mm}$ & $45 \pm 2$ & $61 \pm 10^{*}$ & $58 \pm 7^{*}$ \\
\hline$<55$ & & $26(22)$ & \\
\hline$\geq 55$ & & $84(78)$ & \\
\hline LVEF, \% & $64 \pm 3$ & $39 \pm 12^{*}$ & $40 \pm 8^{*}$ \\
\hline$<40$ & & $55(50)$ & \\
\hline $40 \sim 49$ & & $33(30)$ & \\
\hline$\geq 50$ & & $22(20)$ & \\
\hline \multicolumn{4}{|l|}{ Baseline medications, n (\%) } \\
\hline ACEI/ARB & & $66(60)$ & $72(65)$ \\
\hline Beta-blocker & & $68(62)$ & $91(83)$ \\
\hline Diuretics & & $87(79)$ & $106(96)$ \\
\hline Aldosterone blocker & & $48(44)$ & $95(86)$ \\
\hline Digoxin & & $22(20)$ & $20(18)$ \\
\hline Nitrate & & $39(35)$ & $33(30)$ \\
\hline \multicolumn{4}{|l|}{ Acute phase treatment, n (\%) } \\
\hline Diuretics & & $110(100)$ & \\
\hline Nitrate & & $79(72)$ & \\
\hline Dopamine & & $31(28)$ & \\
\hline Phosphodiesterase inhibitor & & $20(18)$ & \\
\hline Levosimendan & & $12(11)$ & \\
\hline Noradrenaline & & $32(29)$ & \\
\hline Deslanoside & & $37(34)$ & \\
\hline
\end{tabular}

Table 2. Dynamic changes in plasma CTRP1, BNP and aldosterone levels in patients with congestive heart failure, Data are presented as the mean \pm SD or the median and interquartile range. $* \mathrm{p}<0.05,{ }^{*} \mathrm{p}<0.01$ versus control

\begin{tabular}{llllll}
\hline Characteristics & $\begin{array}{l}\text { Control } \\
(\mathrm{n}=50)\end{array}$ & Admission & $24 \mathrm{~h}$ & $\begin{array}{l}\text { CHF }(\mathrm{n}=110) \\
\text { h }\end{array}$ & Discharge \\
\hline CTRP1, ng/mL & $153 \pm 37$ & $282 \pm 194^{* *}$ & $248 \pm 127^{*}$ & $201 \pm 120^{*}$ & $152 \pm 57$ \\
BNP, pg/mL & $14(10-23)$ & $2498(1143-5000)^{* *}$ & $1679(500-2681)^{* *}$ & $1589(498-2597)^{* *}$ & $788(81-2338)^{* *}$ \\
$\begin{array}{l}\text { Aldosterone, } \\
\text { pmol/L }\end{array}$ & $135 \pm 30$ & $456 \pm 189^{* *}$ & $455 \pm 179^{* *}$ & $409 \pm 190^{* *}$ & $331 \pm 133^{* *}$ \\
\hline
\end{tabular}

Comparison of CTRP1 expression in tissues between the CHF group and NCHF group

We performed immunohistochemistry to illustrate the expression of CTRP1 in human tissues. Tissue specimens were randomly selected from the CHF group $(n=25)$ and the 


\section{Cellular Physiology \begin{tabular}{ll|l} 
and Biochemistry & $\begin{array}{l}\text { DOI: 10.1159/000479915 } \\
\text { Published onlIne: August 14, } 2017\end{array}$ & $\begin{array}{l}\text { C } 2017 \text { The Author(s). Published by S. Karger AG, Basel } \\
\text { www.karger.com/cpb }\end{array}$ \\
\cline { 2 - 3 } Yang et al.: Increasing CYP11B2 Levels and Aldosterone Release Through MAPK Signalling
\end{tabular}}

Fig. 1. Plasma CTRP1 levels in patients with $\mathrm{CHF}$ at admission (a) compared with those in control subjects $\left({ }^{* *} \mathrm{p}<0.01\right)$. (b) According to the NYHA functional class ( $p$-value for trend test=0.001). (c) According to the value of LVEDD ( $\mathrm{p}$-value for trend test=0.002). (d) According to the value of LVEF ( $p$-value for trend test=0.993). The numbers of subjects are shown in the brackets.

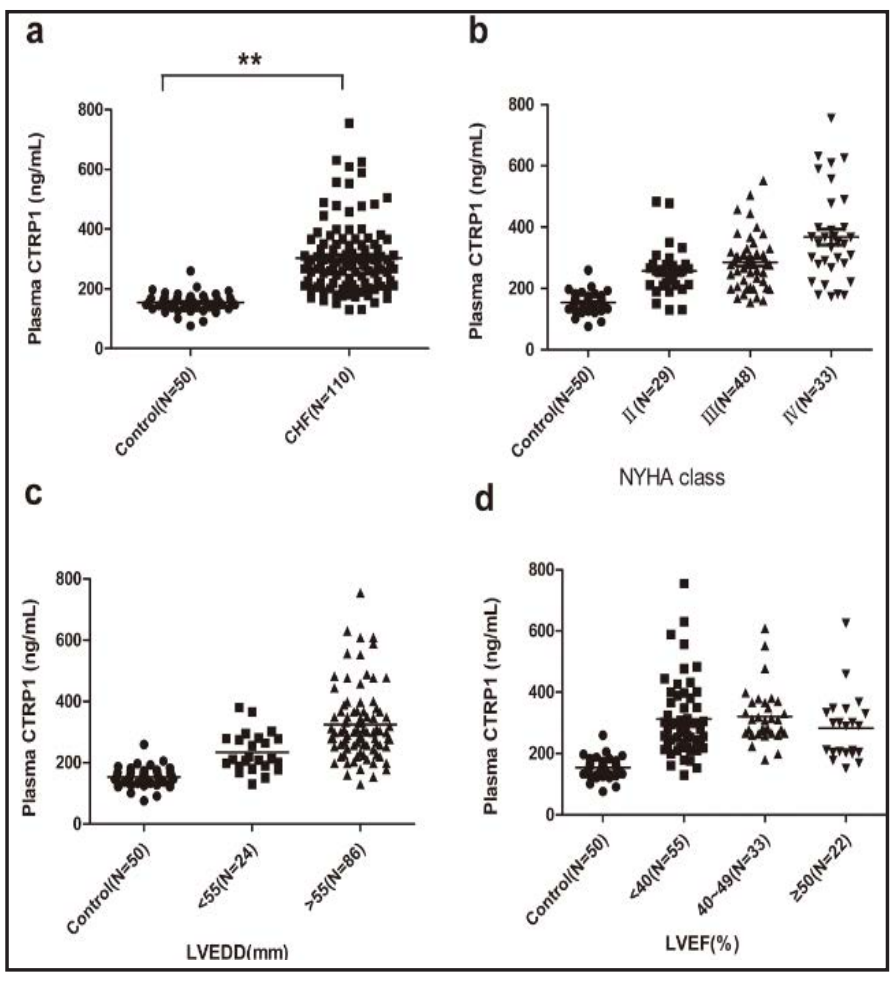

Fig. 2. Plasma CTRP1 levels in patients with CHF. CTRP1 protein was quantified by an ELISA kit at different time points. Data are presented as the mean \pm SD. ${ }^{*} \mathrm{p}<0.05$, $* * \mathrm{p}<0.01$ versus control.

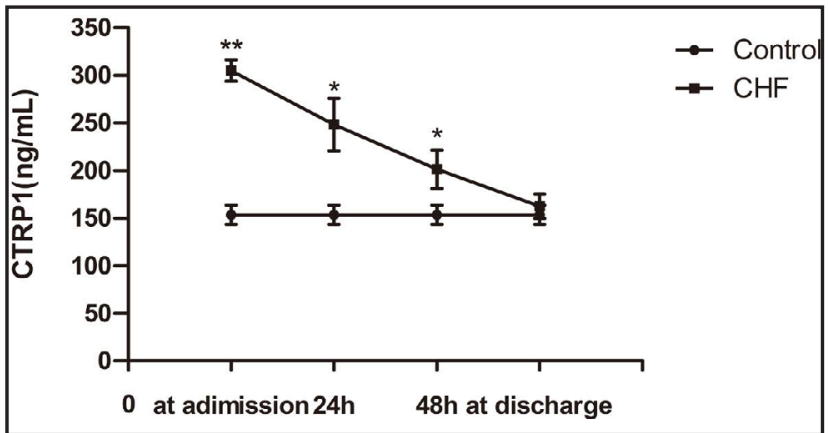

NCHF group $(n=10)$. Fig. 3A-B shows representative immunostained tissue sections from patients with or without CHF. A quantitative analysis of the immunohistochemistry revealed that the amounts of CTRP1 protein in EAT were higher in the patients with CHF than those in patients without CHF (61459 \pm 28419 vs. $48921 \pm 18923, p=0.01$, Fig. $3 \mathrm{~A}-\mathrm{a}, \mathrm{b}, \mathrm{d}$ and C). In all patients who underwent cardiac surgery, significantly higher levels of CTRP1 were found in the EAT than in the SAT $(61459 \pm 28419$ vs. $24682 \pm 9384, p=0.01 ; 48921 \pm 18923$ vs. $27139 \pm 8393, p=0.03$, Fig. $3 \mathrm{~A}-\mathrm{a}, \mathrm{b}, \mathrm{c}$ and C). For the CHF group, the CTRP1 expression in the EAT from the LVEDD $\geq 55$ subgroup was higher than that from the LVEDD $<55$ subgroup (74612 \pm 30456 vs. $50313 \pm 20134, p=0.03$, Fig. $3 A-a, b$ and D). In addition, there was no difference in the CTRP1 expression in the cardiomyocytes between the CHF group and the NCHF group ( $96823 \pm 34785$ vs $99451 \pm 42351, p=0.8$, Fig. 3B,C).

We further assayed the mRNA and protein levels of CTRP1 in human tissues by qRTPCR and Western blotting. In all patients who underwent cardiac surgery, the CTRP1 mRNA expression in the EAT was higher than that in the SAT $(1.1 \pm 0.6$ vs. $0.2 \pm 0.1, p=0.004 ; 0.5 \pm 0.1$ vs. $0.1 \pm 0.1, p=0.02$, Fig. $4 \mathrm{~A}-\mathrm{a}$ ). The CTRP1 mRNA expression in the EAT was markedly increased in the CHF patients compared with that in the NCHF patients $(1.1 \pm 0.6$ vs. $0.5 \pm 0.1$, $p=0.008$, Fig. 4A-a). In the CHF group, the CTRP1 mRNA expression in the EAT was higher in the LVEDD $\geq 55$ subgroup than that in the LVEDD $<55$ subgroup $(1.8 \pm 0.7$ vs. $0.7 \pm 0.4, p=$ 0.01 , Fig. 4A-b). There was no significant alteration of CTRP1 mRNA expression in the 
Fig. 3. The protein expression levels of the CTRP1 and the mRNA expression levels of inflammatory cytokines in human tissues. A representative slide of adipose tissue from patients in the CHF group (Fig.. 3A-a, EAT of LVEDD $\geq 55$ subgroup; $3 \mathrm{~A}-\mathrm{b}, \mathrm{EAT}$ of $\mathrm{LVEDD}<55$ subgroup; 3A-c, SAT) and NCHF group (Fig.. 3A-d, EAT; 3A-e, SAT) (magnified×200). B Representative slides of myocardium from patients in the CHF group (Fig.. $3 \mathrm{~B}-\mathrm{a}$ ) and NCHF group (Fig.. 3B-b) (magnified $\times 200$ ). C Results of the quantitative immunohistochemical analysis of CTRP1 in the EAT and SAT from patients in the two groups (CHF group, $\mathrm{n}=25$; NCHF group, $\mathrm{n}=10$ ) and CTRP1 in the cardiomyocytes from patients in the two groups (CHF group, $\mathrm{n}=$ 13; NCHF group, $n=4$ ). D Results of the quantitative immunohistochemical analysis of CTRP1 in the

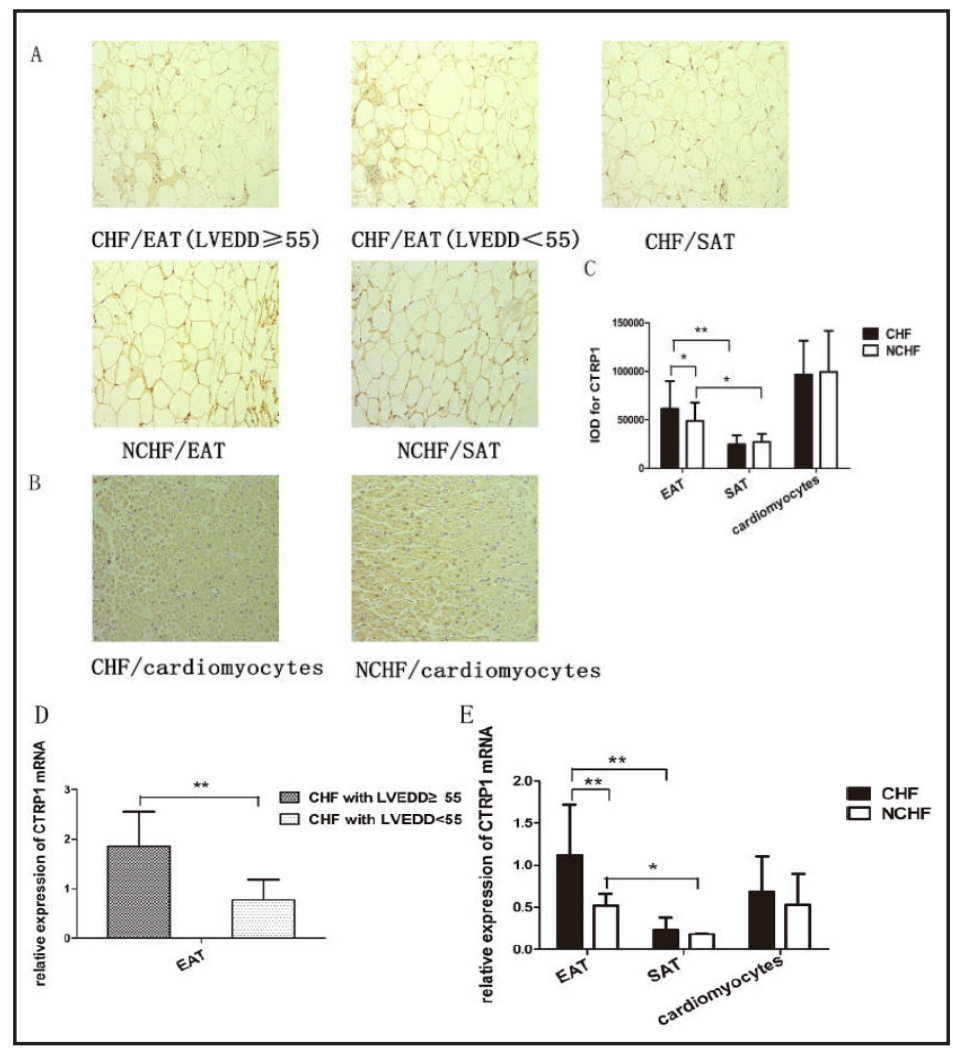
EAT from patients in the CHF group (total, $n=25$; LVEDD $\geq 55$ subgroup, $n=17$; LVEDD $<55$ subgroup, $n=8$ ). E mRNA levels of TNF- $\alpha$ and IL-1 $\beta$ in the EAT from patients in the two groups (CHF group, $n=25$; NCHF group, $\mathrm{n}=10$ ). ${ }^{*} \mathrm{p}<0.05,{ }^{* *} \mathrm{p}<0.01$. CHF congestive heart failure, NCHF non-congestive heart failure, EAT epicardial adipose tissue, SAT subcutaneous adipose tissue, IOD integrated optical density.

Fig. 4. The mRNA and protein expression levels of CTRP1 in human tissues. A-a mRNA levels of CTRP1 in paired EAT and SAT from patients in the two groups (CHF group, $\mathrm{n}$ = 25; NCHF group, $\mathrm{n}$ $=10$ ), mRNA levels of CTRP1 in cardiomyocytes from patients in the two groups (CHF group, $\mathrm{n}=13$; NCHF group, $\mathrm{n}=4$ ); A-b mRNA levels of CTRP1 in the EAT from patients in the CHF group (total, $\mathrm{n}=25$; LVEDD $\geq 55$ subgroup, $\mathrm{n}=17$; LVEDD<55 subgroup, $\mathrm{n}=8$ ). B-a protein levels of CTRP1 in paired EAT and SAT from patients in the CHF group and the NCHF group. B-b protein levels of CTRP1 in the cardiomyocytes from patients in the CHF group and the NCHF group. ${ }^{*} \mathrm{p}<0.05,{ }^{* *} \mathrm{p}<0.01$. CHF congestive heart failure, NCHF non-congestive heart failure, EAT epicardial adipose tissue, SAT subcutaneous adipose tissue.

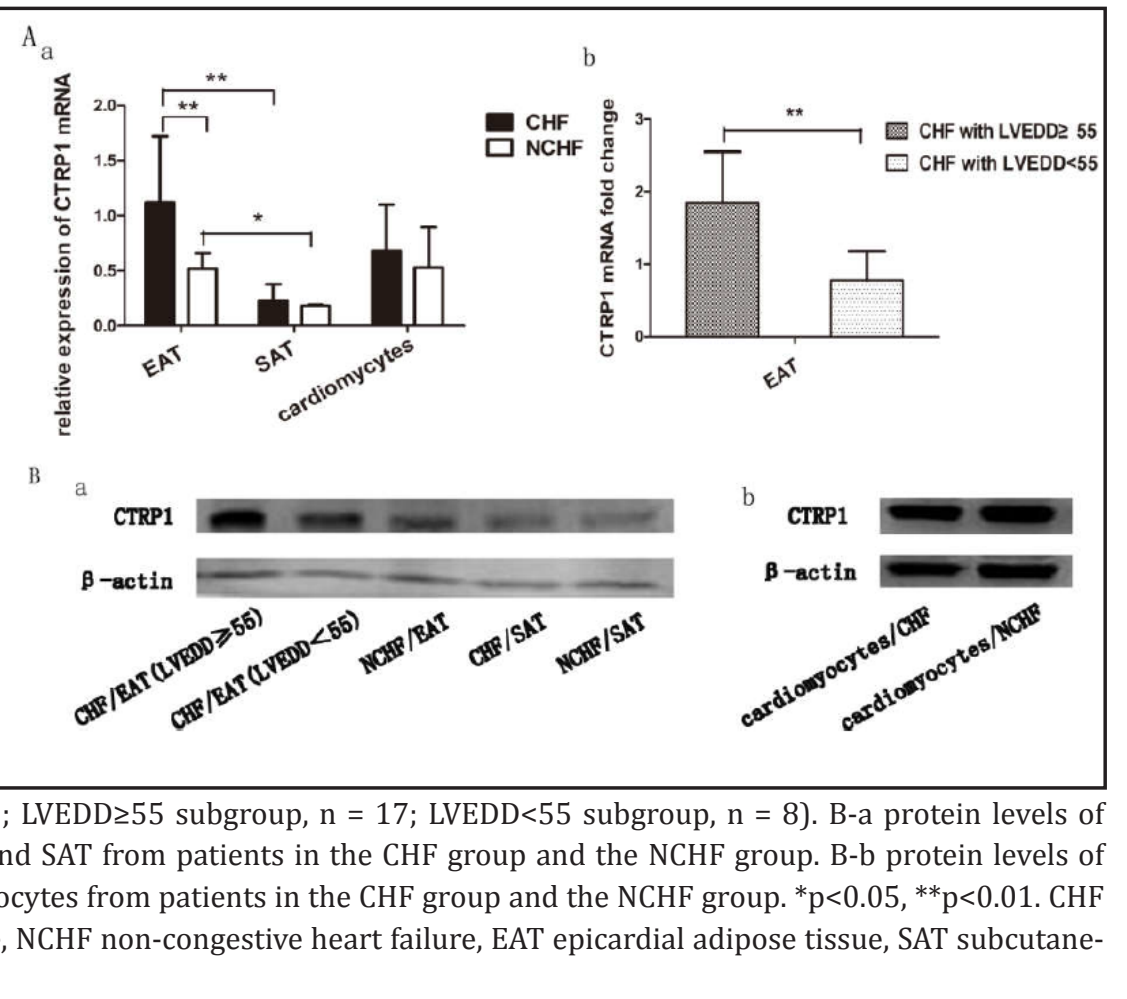




\section{Cellular Physiology \begin{tabular}{ll|l} 
and Biochemistry Published online: August 14, 2017 & $\begin{array}{l}\text { (c) } 2017 \text { The Author(s). Published by S. Karger AG, Basel } \\
\text { www.karger.com/cpb }\end{array}$
\end{tabular} \\ Yang et al.: Increasing CYP11B2 Levels and Aldosterone Release Through MAPK Signalling Pathways}

Table 3. Association among EAT, plasma levels of CTRP1 and other variables via a multivariate regression analysis, "Adjusted for age, sex, BMI, blood pressure level, total cholesterol, total triglyceride and fasting blood glucose

\begin{tabular}{lllllll}
\hline Variables & \multicolumn{3}{l}{ EAT protein levels } & \multicolumn{4}{l}{ Plasma levels } \\
& r & OR $(95 \% \mathrm{CI})^{\#}$ & P-value & r & OR $(95 \% \text { CI) })^{\#}$ & P-value \\
\hline lgBNP & 0.5 & -0.6 to 0.8 & 0.01 & 0.4 & 0.02 to 1.3 & 0.05 \\
lghs-CRP & 0.6 & 0.01 to 2.7 & 0.001 & 0.8 & 0.1 to 1.4 & 0.07 \\
hsTnI & 0.7 & 0.05 to 3.2 & 0.01 & 0.2 & -0.005 to 0.9 & 0.5 \\
aldosterone & 0.6 & 0.02 to 1.9 & 0.001 & 0.5 & 0.1 to 2.5 & 0.001 \\
TNF- $\alpha$ & 0.3 & -0.04 to 0.6 & 0.03 & 0.5 & 0.1 to 0.9 & 0.05 \\
IL-1 $\beta$ & 0.6 & -0.007 to 2.0 & 0.03 & 0.4 & 0.03 to 1.2 & 0.05 \\
IL-6 & 0.5 & 0.1 to 1.5 & 0.04 & 0.5 & 0.005 to 0.9 & 0.05 \\
LVEDD & 0.3 & 0.1 to 0.6 & 0.02 & 0.6 & 0.4 to 3.7 & 0.05 \\
\hline
\end{tabular}

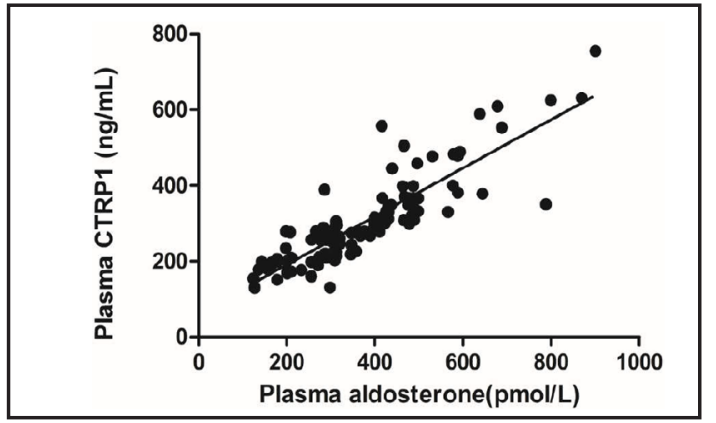

Fig. 5. Relationship between the plasma CTRP1 level and plasma aldosterone in patients with congestive heart failure $(\mathrm{p}=0.001, \mathrm{r}=0.598, \mathrm{n}=110)$.

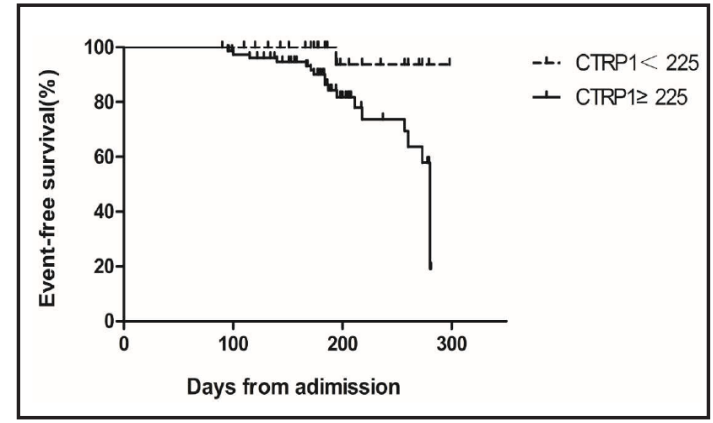

Fig. 6. Kaplan-Meier plot showing the survival rate in patients with CTRP1 above and below $225 \mathrm{ng} / \mathrm{mL}$. $\mathrm{p}=0.02$.

cardiomyocytes between the CHF group and the NCHF group (0.3 \pm 0.2 vs. $0.5 \pm 0.2, p=0.1$, Fig. 4a). We also investigated CTRP1 protein expression in the EAT, SAT and cardiomyocytes in all patients, and the changes were comparable in magnitude with the mRNA expression changes in these tissues (Fig. 4B).

Comparison of inflammatory cytokine mRNA expression in the EAT between the CHF group and NCHF group

By qRT-PCR, we found that the mRNA expression of TNF- $\alpha$ and IL-1 $\beta$ in the EAT from the CHF patients was significantly increased compared with that from the NCHF patients ( $4.8 \pm 1.7$ vs. $0.7 \pm 0.2, p=0.003 ; 6.3 \pm 2.4$ vs. $1.0 \pm 0.4, p=0.005$, Fig. $3 \mathrm{E}$ ).

\section{Association between CTRP1 with other clinical parameters}

The correlations between the CTRP1 levels in the plasma/EAT and several clinical parameters in the CHF patients are shown in Table 3. In the multiple regression analysis, the plasma aldosterone level was an independent factor contributing to the CTRP1 levels in the plasma/EAT in the CHF patients ( $\mathrm{r}=0.6, p=0.001 ; \mathrm{r}=0.5, p=0.001$ ) (Table 3; Fig. 5). There was a tendency towards a positive correlation between the CTRP1 levels in the plasma/EAT and several clinical parameters in the CHF patients, such as BNP, TNF- $\alpha$, IL-1 $\beta$, IL- 6 and LVEDD (Table 3).

\section{Prognosis}

The mean follow-up period after the index admission was 188 days (range: 90-298 days). During the follow-up, 4 patients died, and 15 patients were readmitted due to worsening of heart failure. An exploratory survival analysis was performed with the composite endpoints of cardiac death and readmission for worsening of heart failure. A higher CTRP1 value at admission was associated with a worse prognosis (Fig. 6). 


\section{Cellular Physiology and Biochemistry

Fig. 7. CTRP1 protein increased the production of aldosterone by stimulating CYP11B2 expression. (a) CYP11B2 protein was examined by Western blotting at different time points in H295R cells. (b) Levels of aldosterone were quantified by an ELISA kit at different time points in H295R cells. (c) IL-6 mRNA levels were quantified by RT-PCR at different time points in H295R cells. Three independent experiments were performed in triplicate. ${ }^{*} \mathrm{p}<0.05 ;{ }^{* *} \mathrm{p}<0.01$ versus control.
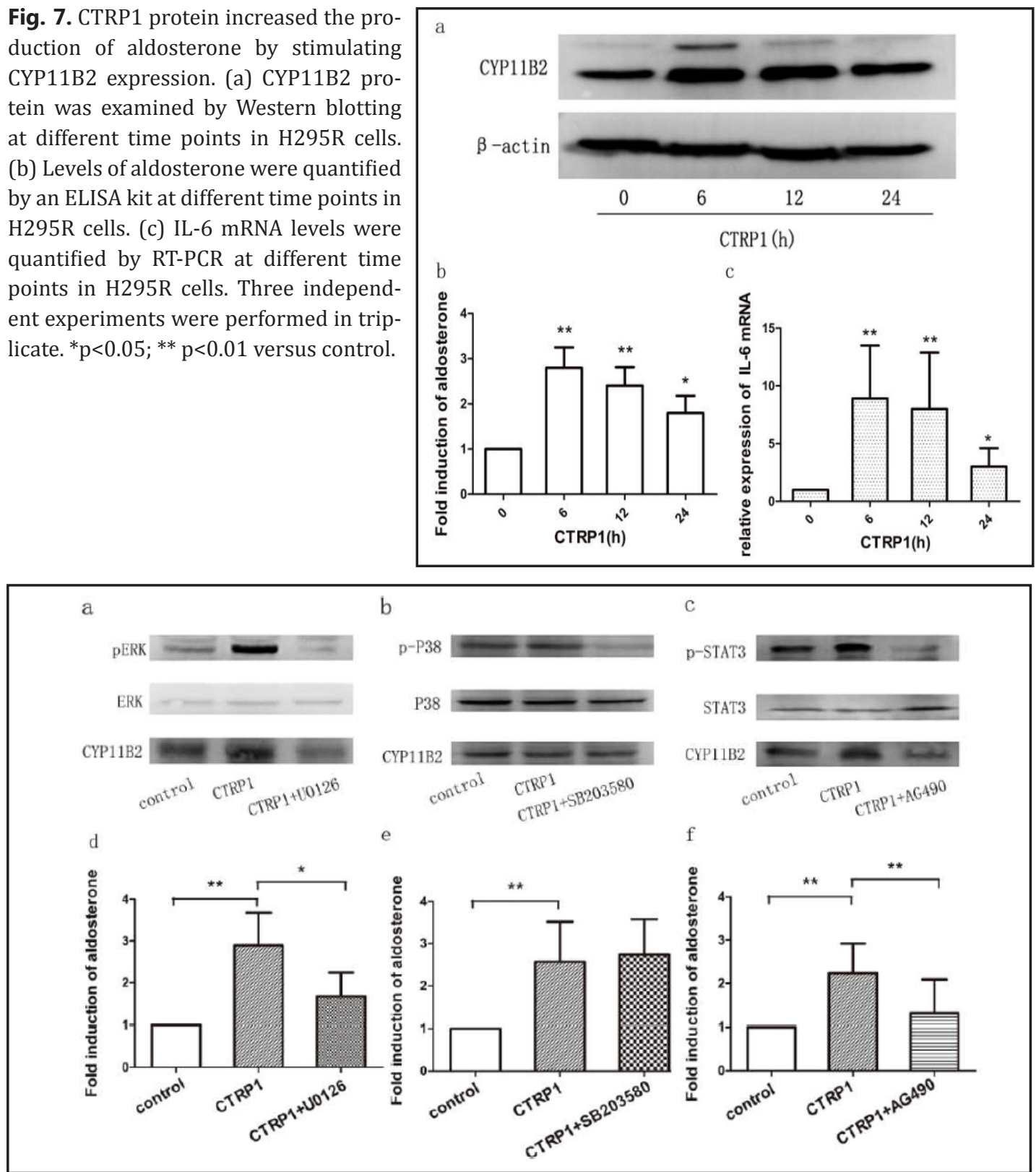

Fig. 8. CTRP1-mediated aldosterone release involved the MAPK signalling pathway. Effect of a MEK inhibitor U0126 (10 $\mu \mathrm{mol} / \mathrm{l}), \mathrm{b}$ p38 MAP kinase inhibitor SB203580 (10 $\mu \mathrm{mol} / \mathrm{l})$ and c Jak-2 inhibitor AG490 (50 $\mu \mathrm{mol} / \mathrm{l})$ on CYP11B2 protein levels. H295R cells were treated with CTRP1 (40 ng/mL) or phosphate buffer solution (PBS) in the presence or absence of U0126, SB203580 and AG490 for $24 \mathrm{~h}$. d-f aldosterone quantifications were performed in the culture supernatants. Three independent experiments were performed in triplicate. ${ }^{*} \mathrm{p}<0.05 ;{ }^{* *} \mathrm{p}<0.01$.

CTRP1 induced aldosterone secretion by enhancing the synthesis of CYP11B2 aldosterone synthase

The production of aldosterone synthase (CYP11B2) and aldosterone were examined by treating H295R cells with recombinant human CTRP1 at various time intervals at a concentration of $40 \mathrm{ng} / \mathrm{mL}$. The CYP11B2 protein expression as analysed by Western blotting peaked at $6 \mathrm{~h}$ and decreased after $24 \mathrm{~h}$ (Fig. 7a). Simultaneously, the level of aldosterone production in the H295R cells as measured by ELISA peaked at $6 \mathrm{~h}$ and decreased after 24 h (Fig. 7b). 


\section{Cellular Physiology \begin{tabular}{ll|l} 
DOI: 10.1159/000479915 & $\begin{array}{l}\text { O 2017 The Author(s). Published by S. Karger AG, Basel } \\
\text { www.karger.com/cpb }\end{array}$ \\
\hline
\end{tabular} \\ Yang et al.: Increasing CYP11B2 Levels and Aldosterone Release Through MAPK Signalling Pathways}

Fig. 9. BNP impeded the CTRP1-induced CYP11B2 expression and aldosterone release in H295R cells through the JAK2-STAT3 signalling pathways. (a) Effect of BNP on CYP11B2 protein expression. H295R cells were incubated with $10^{-6} \mathrm{~mol} / \mathrm{L}$ of BNP for 30 min and then treated for 12 $\mathrm{h}$ with $40 \mathrm{ng} / \mathrm{ml}$ of CTRP1. Subsequently, (b) supernatants were used for the aldosterone measurement.

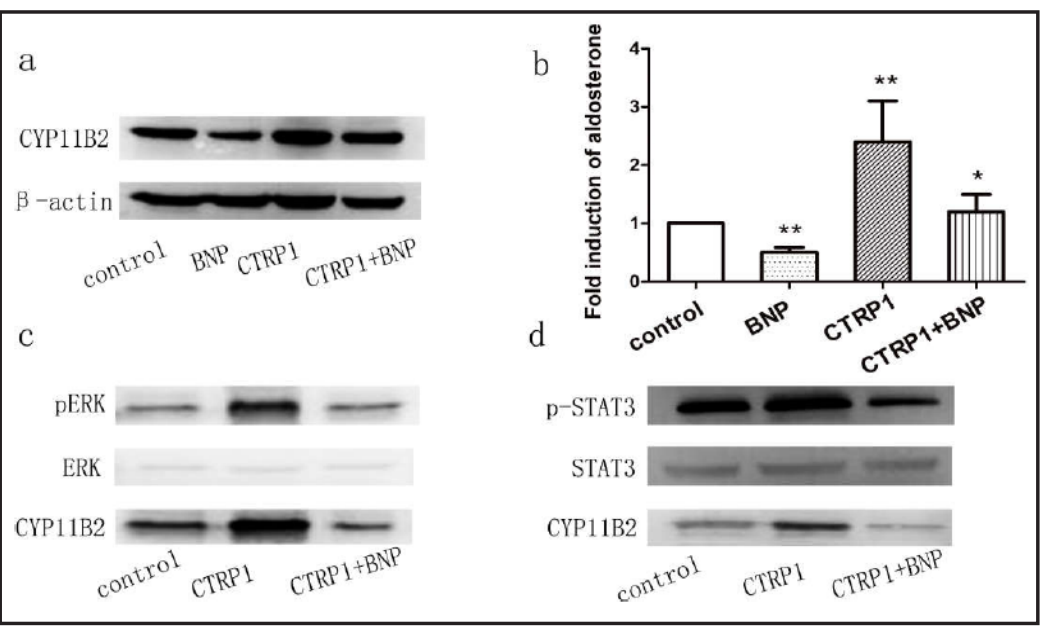
(c-d) The phosphorylation of STAT3, but not of ERK, was attenuated in the co-treatment group. Three independent experiments were performed in triplicate. ${ }^{*} \mathrm{p}<0.05 ;{ }^{* *} \mathrm{p}<0.01$.

\section{CTRP1 increased IL-6 secretion in H295R cells}

H295R cells were incubated with $40 \mathrm{ng} / \mathrm{mL}$ of CTRP1 for different time periods from 0 to $24 \mathrm{~h}$. The IL- 6 mRNA expression in the culture supernatants peaked at $6 \mathrm{~h}$ and began to decrease at $12 \mathrm{~h}$ (Fig. $7 \mathrm{c}$ ).

CTRP1 mediated CYP11B2 expression and aldosterone release through the MAPK signalling pathways

To investigate the role of the MAP kinases in the CTRP1-mediated aldosterone secretion, H295R cells were incubated with CTRP1 in the presence or absence of the MEK (an upstream regulator of ERK1/2) inhibitor U0126 $(10 \mu \mathrm{mol} / \mathrm{l})$, p38 MAP kinase inhibitor SB203580 $(10 \mu \mathrm{mol} / \mathrm{l})$ and Jak-2 inhibitor AG490 (50 $\mathrm{mol} / \mathrm{l})$ for $24 \mathrm{~h}$, and the supernatants were collected for the aldosterone measurement. Whole cell lysates were utilized for the protein isolation, followed by the CYP11B2 protein level quantification by Western blotting. Our study indicated that CTRP1 activated the phosphorylation of ERK and STAT3 in the H295R cells, and there were no significant differences in the ERK and STAT3 protein levels (Fig. 8a, c). Both U0126 and AG490 significantly impeded the CTRP1-induced aldosterone release and CYP11B2 protein expression (Fig. 8a, c, d, f). In contrast, SB203580 had no effect on the CTRP1-induced aldosterone release and CYP11B2 protein expression (Fig. 8b, e).

BNP impeded the CTRP1-induced CYP11B2 expression and aldosterone release through the JAK2-STAT3 signalling pathways

Moreover, we tested whether BNP mediated the CTRP1-induced CYP11B2 expression and aldosterone release. To test this hypothesis, H295R cells were incubated with $10^{-6} \mathrm{~mol} / \mathrm{L}$ of BNP for $30 \mathrm{~min}$ and then treated for $12 \mathrm{~h}$ with $40 \mathrm{ng} / \mathrm{mL}$ of CTRP1. The CYP11B2 protein level in the H295R cells and the aldosterone concentration in the culture supernatants were examined. The results showed that compared with the CTRP1 group, both CYP11B2 and aldosterone protein expression were repressed in the co-treatment group (Fig. 9a-b). The phosphorylation of STAT3 was attenuated in the co-treatment group (Fig. 9c-d).

\section{Discussion}

In this cross-sectional observational study, we demonstrated that in the plasma and EAT, the CTRP1 levels in the CHF patients were significantly higher than those in the NCHF patients, whereas the CTRP1 levels in the cardiomyocytes were not markedly different 
between the two groups. Moreover, the CTRP1 expression in the plasma and EAT were positively correlated with the value of LVEDD. This study also suggested that CTRP1 might provide prognostic information in CHF patients independently of age, gender and LVEF. We further observed that CTRP1 caused a significant induction of IL-6 gene expression in H295R cells. CTRP1 recruited ERK1/2 and Jak-2 for aldosterone release through the modulation of the CYP11B2 protein level, and BNP repressed the CTRP1-induced aldosterone release through the JAK2-STAT3 signalling pathways.

Our experiments revealed that the plasma CTRP1 levels were increased in the CHF patients regardless of the cause of the heart failure. Some previous reports have suggested that the CTRP1 levels were increased in patients with stable coronary heart disease and mice with acute ischaemic injury [20,21]. In this study, we excluded patients with acute myocardial infarction and found dynamic changes in the plasma concentration of CTRP1 in CHF patients. Furthermore, the plasma CTRP1 levels were elevated in CHF caused by nonischaemic cardiomyopathy and ischaemic cardiomyopathy. It was likely that the secretion of CTRP1 was stimulated by the overall inflammatory status in CHF. It is known that adiponectin, which is another important circulating adipocytokine, shares multiple common biochemical features with CTRPs and both have a similar globular head and trimetric basic protein structure [22]. In the diabetic state, in which the levels of adiponectin are low, CTRP1 exhibited a compensatory upregulation [5]. Takahiro Ohara et al. reported that the plasma adiponectin levels increased according to the severity of the ventricular dysfunction in CHF [23]. However, our data demonstrated that an augmented release of CTRP1 was involved in the pathogenesis of CHF. Therefore, our result indicated that some adipokines played different pathophysiological roles in various diseases, even though they shared similar domain structures.

Previous studies have highlighted that CTRP1 was associated with indexes of obesity. In our study, no significant difference of BMI was found between the CHF group and the control group. This result was consistent with a previous study reported by Lin Lu, who speculated that the inflammatory status might be a stronger stimulator to CTRP1 secretion in CHF than the adipose tissue mass [24, 25]. Moreover, some patients with CHF could have gained weight due to water-sodium retention.

Our data showed that the plasma CTRP1 levels increased according to the severity of the NYHA class, and the CTRP1 expression in the plasma and EAT were positively correlated with the value of LVEDD. However, no statistically significant association was found between the plasma CTRP1 levels and LVEF in the CHF patients. We hypothesized that CTRP1 was released from the tissues under the augment of cardiac pressures and the pathological ventricular wall distention in CHF; therefore, CTRP1 might be involved in ventricular remodelling. Furthermore, the prognostic results also showed that the higher plasma CTRP1 levels in CHF related to a worse prognosis or future deterioration of cardiac function.

Previous studies have reported that CTRP1 mRNA is expressed in the heart, placenta, liver, muscle and kidney and the highest expression levels are in adipose tissue [6]. We observed that in the CHF patients, the plasma and EAT CTRP1 levels were markedly higher than those in the NCHF patients. It is reasonable to speculate that the difference in the circulating CTRP1 level between the CHF group and the NCHF group might be partly due to the difference in the secretion of CTRP1 in the EAT. We found that the CTRP1 expression was significantly higher in the EAT than in the paired SAT in the CHF patients, but there was no significant difference in the CTRP1 levels in the cardiomyocytes between the two groups. We also found that pro-inflammatory adipocytokines, such as TNF- $\alpha$ and IL-6, in the EAT were significantly increased in the CHF patients. In animal studies, an LPS treatment caused TNF- $\alpha$ - and IL-1 $\beta$-induced elevations of CTRP1 levels in adipose tissue [17]. Our experiments further revealed that the IL- 6 mRNA level was elevated in the H295R cells by a treatment with CTRP1.

In the present study, we demonstrated that the CTRP1 levels in the plasma and EAT had a positive correlation with plasma aldosterone levels. Jun et al. reported that CTRP1 was expressed in the zona glomerulosa of the adrenal cortex and stimulated aldosterone 


\section{Cellular Physiology Cell Physiol Biochem 2017;42:2130-2143

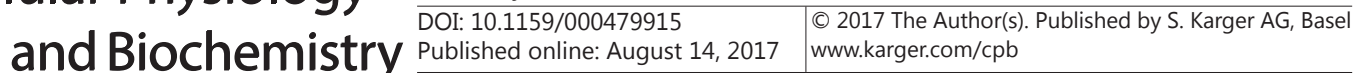 \\ Yang et al.: Increasing CYP11B2 Levels and Aldosterone Release Through MAPK Signalling \\ Pathways}

production by inducing CYP11B2 gene expression . However, Teruhiko et al. indicated that natriuretic peptides reduced CYP11B2 mRNA expression in cultured neonatal rat cardiocytes [26]. Our experiments revealed that CTRP1 increased the protein expression of aldosterone synthase, and the secretion of aldosterone depended partially on the stimulation of the expression of P-ERK1/2 and P-STAT3. U0126 and AG490 significantly decreased the CTRP1mediated aldosterone secretion in the H295R cells. These results indicated that CTRP1 employed ERK1/2 and Jak-2 as the downstream targets of aldosterone secretion and protein regulation of aldosterone synthase. In contrast, we observed that BNP inhibited the CTRP1mediated aldosterone synthase protein expression and aldosterone secretion by attenuating ERK1/2 activation. This finding suggested that CTRP1 and BNP might play opposite roles in the pathogenesis of CHF.

Most importantly, we hypothesized that in CHF patients, pro-inflammatory adipocytokines, such as TNF- $\alpha$ and IL-1 $\beta$, in the plasma and EAT, induced EAT CTRP1 secretion, and the EAT-derived CTRP1 moved into the local coronary artery via paracrine mechanisms and was then transported to the blood cycle. Circulating CTRP1 might partly affect the pathogenesis of CHF by stimulating the release of aldosterone and IL- 6 in adrenal cortical cells.

Several limitations of the present study should be considered. The characteristics of the subjects in the CHF group and the control group were not completely balanced, which may have confounded the association between the CTRP1 expression and CHF. Due to the restriction of the number of EAT biopsy samples, it was not possible to investigate the association between the EAT CTRP1 levels and NYHA classes or LVEF in CHF. We also did not detect the levels of CTRP1 secretion from the EAT and cardiomyocytes. Because we did not obtain cardiomyocyte samples from patients with different sicknesses, we only measured the CTRP1 level in cardiomyocytes from patients with valvular replacement.

\section{Conclusion}

Our study demonstrated that the levels of CTRP1 in the plasma and EAT were higher in the CHF patients. The plasma and EAT CTRP1 levels were positively associated with the value of LVEDD. Higher plasma CTRP1 values at admission might be a sign of low treatment responsiveness in CHF. Furthermore, CTRP1 increased IL-6 secretion in H295R cells. CTRP1 recruited extracellular signal-regulated kinase (ERK1/2 and JAK2) as a downstream regulator for the modulation of CYP11B2 protein level and aldosterone release. However, further studies are necessary to explain the precise role of CTRP1 in CHF.

\section{Acknowledgements}

This study was supported by a General Financial Grant from the China Postdoctoral

Science Foundation (grant number: 2016M592678, Beijing, China), a General Financial Grant from the Education Department of Sichuan province (grant number: 17ZB0168, Chengdu, China) and a General Financial Grant from the Science and Technology Department of Sichuan Province (grant number: 2016JY0172, Chengdu, China).

\section{Disclosure Statement}

None declared. 


\section{Cellular Physiology Cell Physiol Biochem 2017;42:2130-2143 \begin{tabular}{ll|l} 
and Biochemistry Published onlıne: August 14, 2017 & $\begin{array}{l}\text { (c) } 2017 \text { The Author(s). Published by S. Karger AG, Basel } \\
\text { www.karger.com/cpb }\end{array}$
\end{tabular} \\ Yang et al.: Increasing CYP11B2 Levels and Aldosterone Release Through MAPK Signalling}

Pathways

\section{References}

1 Withers SB, Bussey CE, Saxton SN, Melrose HM, Watkins AE, Heagerty AM: Mechanisms of adiponectinassociated perivascular function in vascular disease. Arterioscler Thromb Vasc Biol 2014;34:1637-1642.

2 Iacobellis G: Local and systemic effects of the multifaceted epicardial adipose tissue depot. Nat Rev Endocrinol 2015;11:363-371.

3 Iacobellis G, Corradi D, Sharma AM: Epicardial adipose tissue: Anatomic, biomolecular and clinical relationships with the heart. Nat Clin Pract Cardiovasc Med 2005;2:536-543.

-4 Ohashi K, Shibata R, Murohara T, Ouchi N: Role of anti-inflammatory adipokines in obesity-related diseases. Trends Endocrinol Metab 2014;25:348-355.

-5 Wong GW, Wang J, Hug C, Tsao TS, Lodish HF: A family of acrp30/adiponectin structural and functional paralogs. Proc Natl Acad Sci U S A 2004;101:10302-10307.

-6 Schaffler A, Buechler C: Ctrp family: Linking immunity to metabolism. Trends in endocrinology and metabolism: Trends Endocrinol Metab 2012;23:194-204.

7 Xin Y, Lyu X, Wang C, Fu Y, Zhang S, Tian C, Li Q, Zhang D: Elevated circulating levels of ctrp1, a novel adipokine, in diabetic patients. Endocr J 2014;61:841-847.

-8 Davis KE, Scherer PE: Adiponectin: No longer the lone soul in the fight against insulin resistance? Biochem J 2008;416:e7-9.

9 Lasser G, Guchhait P, Ellsworth JL, Sheppard P, Lewis K, Bishop P, Cruz MA, Lopez JA, Fruebis J: C1qtnfrelated protein-1 (ctrp-1): A vascular wall protein that inhibits collagen-induced platelet aggregation by blocking vwf binding to collagen. Blood 2006;107:423-430.

10 van Hinsbergh VW, Eringa EC: C1q/tnf-related protein 1: A novel link between visceral fat and atheroinflammation. Eur Heart J 2016;37:1772-1774.

11 Jeon JH, Kim KY, Kim JH, Baek A, Cho H, Lee YH, Kim JW, Kim D, Han SH, Lim JS, Kim KI, Yoon DY, Kim SH, Oh GT, Kim E, Yang Y: A novel adipokine ctrp1 stimulates aldosterone production. FASEB J 2008;22:1502-1511.

$\checkmark 12$ Ghosh RK, Ball S, Prasad V, Gupta A: Depression in heart failure: Intricate relationship, pathophysiology and most updated evidence of interventions from recent clinical studies. Int J Cardiol 2016;224:170-177.

-13 Cezar MD, Damatto RL, Pagan LU, Lima AR, Martinez PF, Bonomo C, Rosa CM, Campos DH, Cicogna AC, Gomes MJ, Oliveira SA, Jr., Blotta DA, Okoshi MP, Okoshi K: Early spironolactone treatment attenuates heart failure development by improving myocardial function and reducing fibrosis in spontaneously hypertensive rats. Cell Physiol Biochem 2015;36:1453-1466.

14 Ponikowski P, Voors AA, Anker SD, Bueno H, Cleland JG, Coats AJ, Falk V, Gonzalez-Juanatey JR, Harjola VP, Jankowska EA, Jessup M, Linde C, Nihoyannopoulos P, Parissis JT, Pieske B, Riley JP, Rosano GM, Ruilope LM, Ruschitzka F, Rutten FH, van der Meer P, Authors/Task Force M, Document R: 2016 esc guidelines for the diagnosis and treatment of acute and chronic heart failure: The task force for the diagnosis and treatment of acute and chronic heart failure of the european society of cardiology (esc). Developed with the special contribution of the heart failure association (hfa) of the esc. Eur Heart J 2016;18:891-975.

-15 Writing Committee M, Yancy CW, Jessup M, Bozkurt B, Butler J, Casey DE Jr, Colvin MM, Drazner MH, Filippatos G, Fonarow GC, Givertz MM, Hollenberg SM, Lindenfeld J, Masoudi FA, McBride PE, Peterson PN, Stevenson LW, Westlake C: 2016 acc/aha/hfsa focused update on new pharmacological therapy for heart failure: An update of the 2013 accf/aha guideline for the management of heart failure: A report of the american college of cardiology/american heart association task force on clinical practice guidelines and the heart failure society of america. Circulation 2016;134:e282-293.

16 Madamanchi C, Alhosaini H, Sumida A, Runge MS: Obesity and natriuretic peptides, bnp and nt-probnp: Mechanisms and diagnostic implications for heart failure. Int J Cardiol 2014;176:611-617.

17 Kim KY, Kim HY, Kim JH, Lee CH, Kim DH, Lee YH, Han SH, Lim JS, Cho DH, Lee MS, Yoon S, Kim KI, Yoon DY, Yang Y: Tumor necrosis factor-alpha and interleukin-1beta increases ctrp1 expression in adipose tissue. FEBS Lett 2006;580:3953-3960.

18 Dick SA, Epelman S: Chronic heart failure and inflammation: What do we really know? Circ Res 2016;119:159-176.

19 Metra M, Carubelli V, Ravera A, Stewart Coats AJ: Heart failure 2016: Still more questions than answers. Int J Cardiol 2017;227:766-777. 


\section{Cellular Physiology Cell Physiol Biochem 2017;42:2130-2143}

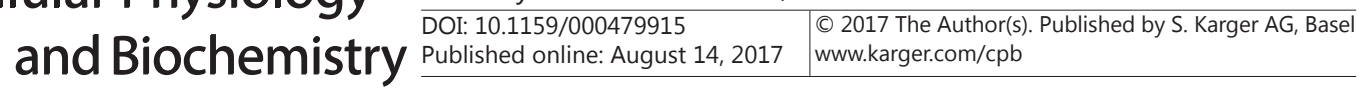

Yang et al.: Increasing CYP11B2 Levels and Aldosterone Release Through MAPK Signalling Pathways

20 Wong GW, Krawczyk SA, Kitidis-Mitrokostas C, Revett T, Gimeno R, Lodish HF: Molecular, biochemical and functional characterizations of c1q/tnf family members: Adipose-tissue-selective expression patterns, regulation by ppar-gamma agonist, cysteine-mediated oligomerizations, combinatorial associations and metabolic functions. Biochem J 2008;416:161-177.

-21 Yuasa D, Ohashi K, Shibata R, Mizutani N, Kataoka Y, Kambara T, Uemura Y, Matsuo K, Kanemura N, Hayakawa S, Hiramatsu-Ito M, Ito M, Ogawa H, Murate T, Murohara T, Ouchi N: C1q/tnf-related protein-1 functions to protect against acute ischemic injury in the heart. FASEB J 2016;30:1065-1075.

-22 Yuasa D, Ohashi K, Shibata R, Takeshita K, Kikuchi R, Takahashi R, Kataoka Y, Miyabe M, Joki Y, Kambara T, Uemura Y, Matsuo K, Hayakawa S, Hiramatsu-Ito M, Ito M, Ikeda N, Murohara T, Ouchi N: Association of circulating c1q/tnf-related protein 1 levels with coronary artery disease in men. PLoS One 2014; 9:e99846.

-23 Peterson JM, Aja S, Wei Z, Wong GW: Ctrp1 protein enhances fatty acid oxidation via amp-activated protein kinase (ampk) activation and acetyl-coa carboxylase (acc) inhibition. J Biol Chem 2012;287:1576-1587.

-24 Ohara T, Hashimura K, Asakura M, Ogai A, Amaki M, Hasegawa T, Kanzaki H, Sonoda M, Nishizawa H, Funahashi T, Kitakaze M: Dynamic changes in plasma total and high molecular weight adiponectin levels in acute heart failure. J Cardiol 2011;58:181-190.

25 Lu L, Zhang RY, Wang XQ Liu ZH, Shen Y, Ding FH, Meng H, Wang LJ, Yan XX, Yang K, Wang HB, Pu LJ, Zhang Q, Chen QJ, De Caterina R, Shen WF: C1q/tnf-related protein-1: An adipokine marking and promoting atherosclerosis. Eur Heart J 2016;37:1762-1771.

-26 Ito T, Yoshimura M, Nakamura S, Nakayama M, Shimasaki Y, Harada E, Mizuno Y, Yamamuro M, Harada M, Saito Y, Nakao K, Kurihara H, Yasue H, Ogawa H: Inhibitory effect of natriuretic peptides on aldosterone synthase gene expression in cultured neonatal rat cardiocytes. Circulation 2003;107:807-810. 